International Research Journal of Management, IT \& Social Sciences
Available online at https://sloap.org/journals/index.php/irjmis/
Vol. 7 No. 3, May 2020, pages: 110-115
ISSN: 2395-7492
https://doi.org/10.21744/irjmis.v7n3.927

\title{
Characterization of Former Athletes with Gonarthrotic of Santiago de Cuba Province
}

\author{
Lisbey Naranjo Abad ${ }^{a}$ \\ Viviana Romero Vidal ${ }^{\mathrm{b}}$ \\ Hilda Rosa Rabilero Sabatés ${ }^{c}$
}

Article history:

Submitted: 18 March 2020

Revised: 27 April 2020

Accepted: 09 May 2020

\section{Keywords:}

former athletes;

gonoartrosis;

injuries in sportsmans;

osteoarthrosis of the knee;

sport;

\begin{abstract}
Gonarthrosis is one of the main causes of pain and disability affecting a large number of the population of former athletes in the provincial Santiago de Cuba. Precisely this research aims to characterize the population of former athletes studied, some qualitative variables of interest, their predominance, and frequency, emphasizing age, sex, sport, and degree of osteoarthritis by the scale of Kellgren and Lawrence; that evaluates the degrees of osteoarthritis observed in X-rays. A percentage of statistical analysis was used for the interpretation of the data. As fundamental results, the group of age intervals of 41 to 50 years with $47 \%$ could be observed; the male sex dominated with equal $50 \%$ percentile for both age groups of 41 to 50 and 61-60 years; games with balls predominated with $71 \%$; and grade II or mild osteoarthrosis in knees predominated with $71.5 \%$.
\end{abstract}

International research journal of management, IT and social sciences (C) 2020. This is an open access article under the CC BY-NC-ND license (https://creativecommons.org/licenses/by-nc-nd/4.0/).

Corresponding author:

Lisbey Naranjo Abad,

Centro Provincial de Medicina Deportiva, Santiago de Cuba, Cuba.

Email address: lisbey78@gmail.com

\footnotetext{
a Centro Provincial de Medicina Deportiva, Santiago de Cuba, Cuba

${ }^{b}$ Centro Provincial de Medicina Deportiva, Santiago de Cuba, Cuba

Universidad de Oriente, Santiago de Cuba, Cuba
} 


\section{Introduction}

Osteorosis (also called osteoarthrosis -OA-) is a degenerative joint disease characterized by a progressive deterioration of hyaline cartilage to the company of synovial and subchondral bone disorders, In the rodilla, also known as gonarthrosis, is a degenerative condition that occurs when changes occur in the mechanical properties of the cartilage and subchondral bone, according to the degree to which such a condition is found generates levels of limitation of functionality by affecting physical function through the presence of pain and stiffness, which in former athletes who suffer from it, reduces the quality of life interfering in their professional and working life. Studies and research carried out to coincide with the results shown in this research (García \& Calcerrada, 2006; Alvarez et al., 2004; De los Santos, 2004).

The main causes of osteoarthritis of the knee are trauma during sports and recreational activities, overload for hard physical work, a congenital deformity of joints metabolic disorders, overweight. The knee joint joins the femur with the tibia. The ends of both bones are covered with cartilage and are held together by a joint capsule. Muscles, ligaments, and tendons ensure the stability of the knee joint. The reason for the high frequency of knee osteoarthritis, compared to other joints of the body, is because the knee is a "load" joint, that is, it has to bear the weight of the body and the objects we carry, when we stand or when we move walking, running, climbing or lowering stairs. The femur, tibia, patella, inside the knee all these bones are coated with cartilage, which serves to prevent the rubbing of bone with bone in the movements of the knee, facilitating the slipping and cushioning the blows (Pihl et al., 2003; Kettunen et al., 2010).

It is precisely the wear and tears over the years and the aging of the cartilage, which gives rise to osteoarthritis, being premature in athletes who start from a very early age where they do not possess the physical fullness, the necessary bone maturation, not defined to face competitive events of magnitude, who suffer strong physical and psychological pressures when exposed to the rigorous demand of sports training; Finally the consequence is premature wear and tear of the components of the osteomyarticular system if the fundamental role of joints is taken into account throughout the body. Excessive physical exercise. Other times knee osteoarthritis occurs as a result of a previous joint injury or abnormality such as injuries to the meniscus, ligaments, or joint bone, following intraarticular bone fractures (Nancy, 2017; De los Santos, 2009).

In Cuba there is a high prevalence of knee joint conditions, almost entirely afflicting people over the age of 60 , consulting literature we check that about $60 \%$ of injuries in sport correspond to the soft tissues of the osteomyarticular system and them, between 40 and $50 \%$ have their origin in the overuse, (repetitive microtrauma), in the case of sport one of the causes that condition the appearance of osteoarthosis, thus coinciding with the literature consulted (Nancy, 2017; Hamilton et al., 2015). According to published results of regenerative therapy and its relationship with effectiveness and effectiveness, it was applied considering benefiting former athletes who are studying, in which there is already an important joint commitment, some authors expose similar results (Hernandez \& Ring, 2016; Fader et al., 2014)

\section{Materials and Methods}

A descriptive study was developed to evaluate qualitative variables of interest and their frequency of onset, to 17 exathlete patients between the ages of 18 and 70 years, (both sexes), who received treatment with regenerative therapy implants for knee osteoarthrosis, all results from a research project carried out at the Provincial Center of Sports Medicine of Santiago de Cuba in the period 2017-2018. For the research, the statistical data emanating from the documentary analysis process (data collection sheets or medical history in the research) were used to analyze and interpret the results (Peter, 2015; Paajanen et al., 2011; Pearson \& Jones, 1992).

The following qualitative variables of interest were evaluated: Age: It was distributed in years and presented by interval scales shown in Figure 1, between ages 18 - 30 years, 31-40 years, 41-50 years, 51-60 years and 61-70 years and in Figure 2, the evaluation by sex: according to the biological sex of belonging (male and female). Sport: According to the sports group that practices shown in Figure 3, in combat, fastness, and speed, time and mark, play with balls and competitive art (Gür et al., 2002; Weidenhielm et al., 1992). Grade of knee osteoarthritis by Kellgren and Lawrence scale evaluates the degrees of osteoarthritis observed in the RX, shown in Figure 4.

a) Osteoarthrosis or Knee Gonarthrosis Grade 0: (Normal)

b) Osteoarthrosis or Grade I Knee Gonarthrosis: (Doubtful)

c) Osteoarthrosis or Grade II Knee Gonarthrosis: (Mild)

Abad, L. N., Vidal, V. R., \& Sabatés, H. R. R. (2020). Characterization of former athletes with gonarthrotic of Santiago de Cuba province. International Research Journal of Management, IT and Social Sciences, 7(3), 110-115. https://doi.org/10.21744/irjmis.v7n3.927 
d) Osteoarthrosis or Grade III Knee Gonarthrosis: (Moderate)

e) Osteoarthrosis or Grade IV Knee Gonarthrosis: (Severe)

\section{Results and Discussions}

The graph in Figure 1 shows the distribution of patients based on age range scales in years fulfilled. Of the 17 former total athletes of the population investigated with knee gonoarthrosis treated with regenerative therapy according to the distribution of patients according to age intervals in years dominated the group of 41 to 50 years with $47 \%$, followed by the group of $61-60$ years with $35.2 \%$ compared to the rest of the age group. According to revised literature, they argue that knee osteoarthritis or gonarthrosis is a condition usually described in patients aged 50 years and over, coinciding with the revised literature, taking into account that this entity is found as a recurring cause of sports injury developed primarily by the overuse of sport in which repetitive microlejury of the components of the knee joint tissue occurs.

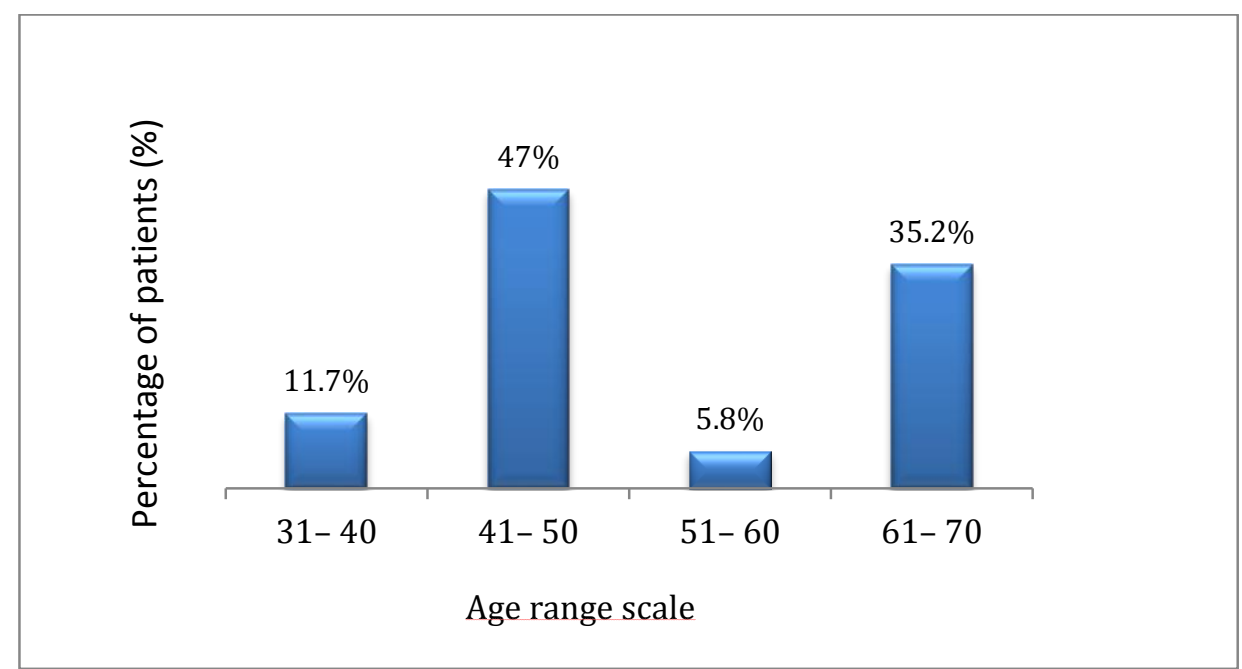

Figure 1. Distribution of patients according to age range scales in years met. No. 17

Figure 2 shows the distribution of patients according to sex and age ranges. Predominantly male with an equal percentage of $50 \%$ for both age groups ages 41 to 50 and $61-60$ years of age, the results do not match the revised literature, as they refer to sex, that female athletes show a higher incidence of knee injuries, in various theories the existence of anatomical differences have been suggested, differences in joint laxity, hormone levels, proprioceptive sensitivity, and training techniques. They have a higher laxity in the knee and show a lower joint proprioceptive sensitivity than men. In our results the male predominance, we think this is because the sample studied in the research, mostly those of the male sex attended, in terms of the busy groups of ages, if it coincides with the discourse in the literature consulted for the female sex. 


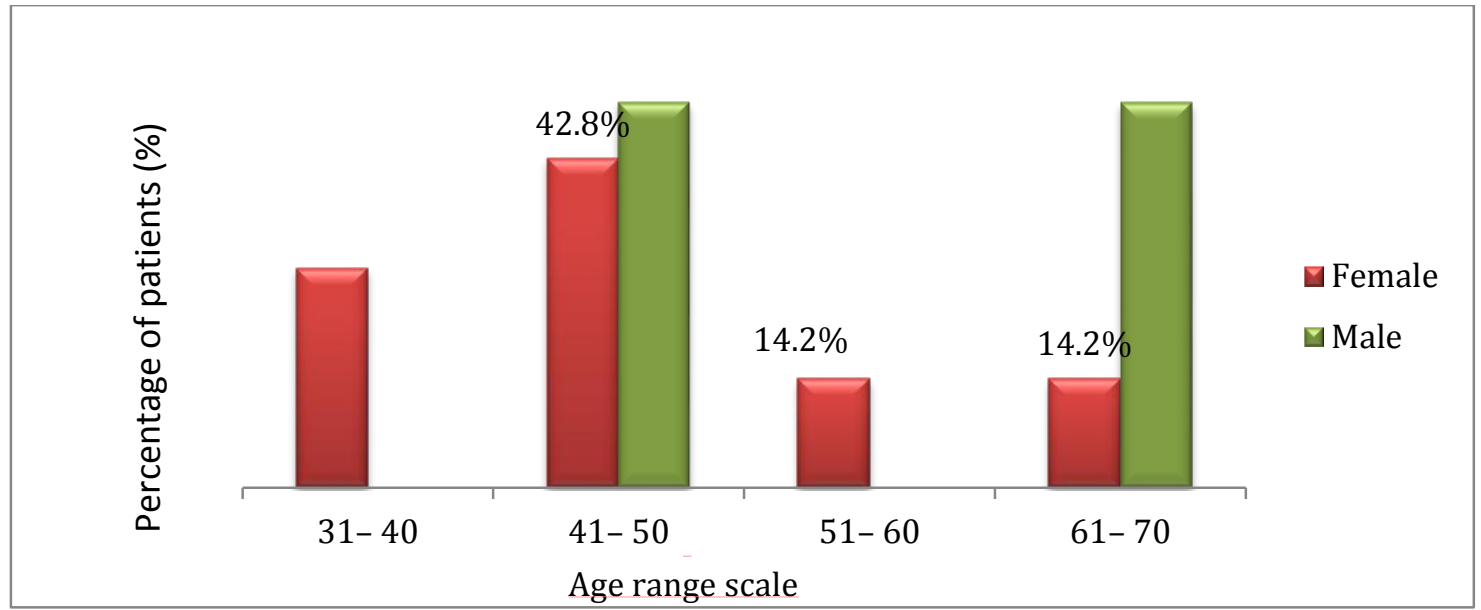

Figure 2. Distribution of patients according to sex and age ranges. F.7 M. 10

In the graph in Figure 3, the distribution of patients is postponed according to the type of sport they practiced. It is shown that those in the game group with balls dominated with $71 \%$, followed by the combat groups with $18 \%$, which coincides with the literature consulted since in Dr. De Los Santos refers that the characteristics of jumps in both defensive and offensive actions, the knee joints remain in constant movement in different directions while receiving continuous micro-traumas to repetition, which make them more vulnerable to injuries including gonoarthrosis.

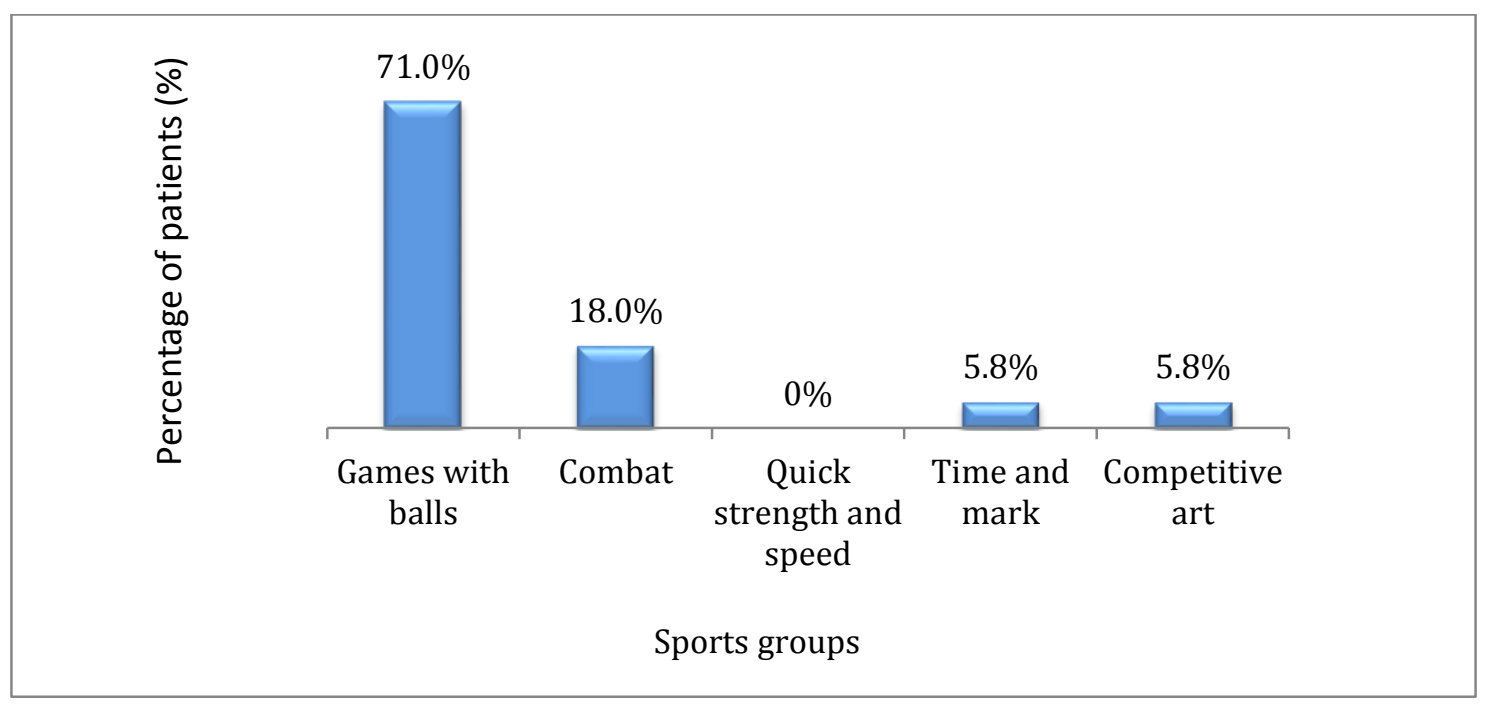

Figure 3. Distribution of patients according to the sports group that he practiced. No. 17

The graph in Figure 4, shows the distribution of osteoarthritis grades in Kellgren and Lawrence scaled knees (García \& Calcerrada, 2006).

Abad, L. N., Vidal, V. R., \& Sabatés, H. R. R. (2020). Characterization of former athletes with gonarthrotic of Santiago de Cuba province. International Research Journal of Management, IT and Social Sciences, 7(3), 110-115. https://doi.org/10.21744/irjmis.v7n3.927 


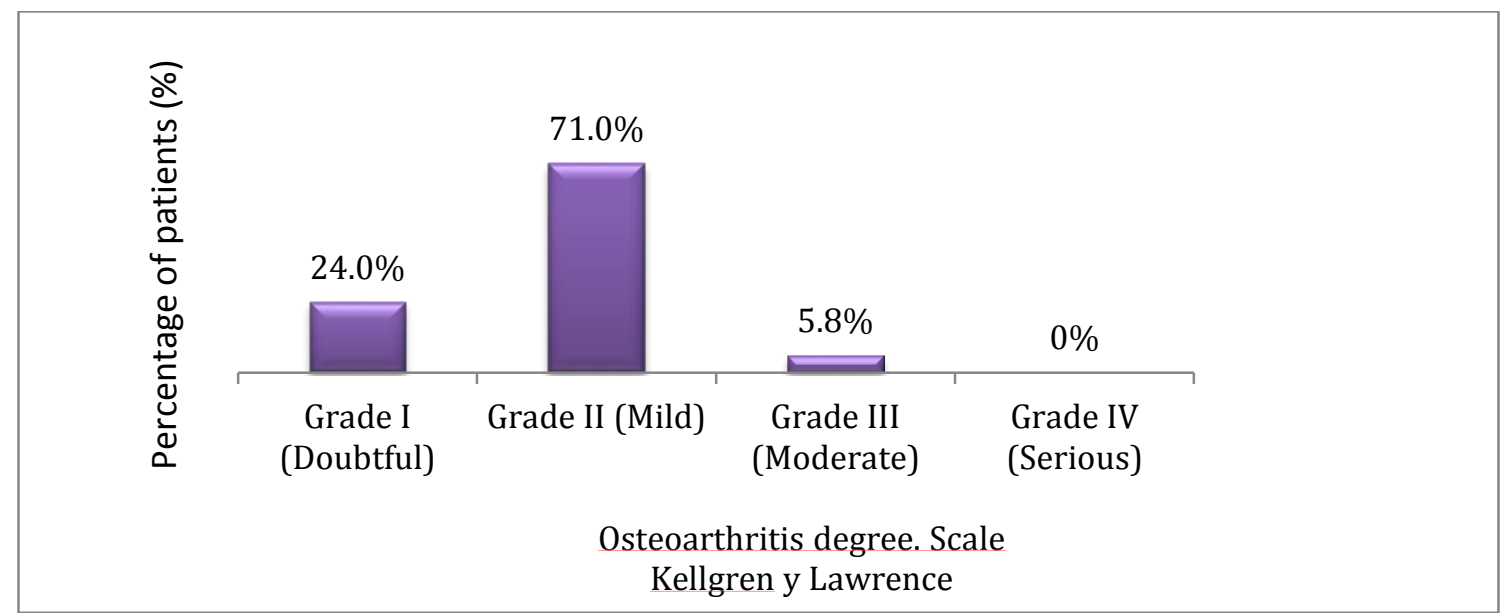

Figure 4. Degree of osteoarthritis in knees by Kellgren and Lawrence scale that evaluates the degrees of osteoarthritis observed in the Rx

In the study, the predominance of grade II or mild knee osteoarthrosis was obtained with $71 \%$, followed by grade I or doubtful with $24 \%$, the results obtained are unrelated to the revised literature, since ex-athletes may present any degree of osteorthrosis in the joint, without predominance over any variable.

\section{Conclusion}

In the research, the characterization of the variables, which allowed to evaluate and compare with consulted literature, the population of former athletes with knee gonoarthrosis who participated in the research resulted and in the predominate in the age group between 41 and 50 years of age, coinciding with the revised literature in which gonarthrosis is usually described in patients aged 50 years or older; which is a recurring cause of sports injury often over sports use, also coincided the predominance of games with balls, in which the knee joint product to the characteristics of the jumps, the constant movement or movements in different directions or directions receive continuous micro-traumas to repetition which make them more vulnerable to the appearance of this injury; in sex is more frequent for the female, the results obtained showed that the male sex is the most vulnerable, valuing it either because they attended more samples in the study. The degrees of osteoarthritis of the knees are not related to predominance regarding the literature if it is as observed or the overuse of the knee joint in the former athletes of the study, a lower or greater degree of ostetorthrosis was found by scales used for radiological evaluations.

\section{Conflict of interest statement}

The authors declared that they have no competing interests.

\section{Statement of authorship}

The authors have a responsibility for the conception and design of the study. The authors have approved the final article.

\section{Acknowledgments}

We are grateful to two anonymous reviewers for their valuable comments on the earlier version of this paper. 


\section{References}

Alvarez, R., Jacobo, M., Marrero, L. O. \& Castro, A. (2004). Soft part injuries in high-performance athletes. Rev. Cuban OrtopTraumatol.; 18(2).

De los Santos, F. (2004). Sports Injury Conference. Master Conference held at the II Santiago de Cuba International Volleyball Symposium.

De los Santos, R. F. (2009). Effectiveness of medium-power laser therapy in soft part lesions of the ankle joint, in the sports community of ESFAR'lsrael Reyes Zayas. Thesis to Opt for a Master's Degree in Science. Santiago de Cuba: Higher Institute of Physical Culture: Faculty Santiago de Cuba "Manuel Fajardo Rivero".

Fader, R. R., Mitchell, J. J., Traub, S., Nichols, R., Roper, M., Dan, O. M., \& McCarty, E. C. (2014). Platelet-rich plasma treatment improves outcomes for chronic proximal hamstring injuries in an athletic population. Muscles, ligaments and tendons journal, 4(4), 461.

Garcia, F. J., \& Calcerrada, N. (2006). Working Group of the Clinical Practice Guide to Patient Management with Knee Osteoarthritis in Primary Care. Madrid: Health Technology Assessment Unit (UETS), Research and Health Studies Area. Entralgo Laín Agency; September.

Gür, H., Çakın, N., Akova, B., Okay, E., \& Küçükoğlu, S. (2002). Concentric versus combined concentric-eccentric isokinetic training: effects on functional capacity and symptoms in patients with osteoarthrosis of the knee. Archives of physical medicine and rehabilitation, 83(3), 308-316. https://doi.org/10.1053/apmr.2002.30620

Hamilton, B., Tol, J. L., Knez, W., \& Chalabi, H. (2015). Exercise and the platelet activator calcium chloride both influence the growth factor content of platelet-rich plasma (PRP): overlooked biochemical factors that could influence PRP treatment. Br J Sports Med, 49(14), 957-960. http://dx.doi.org/10.1136/bjsports-2012-091916

Hernandez, A., \& Ring, R. (2016). Regenerative medicine and sports medicine, a fruitful integration: introduction and advances in Cuba. Cuban Journal of Hematology, Immunology and Hemotherapy [Internet Magazine]. [Cited 2017 Mar 9]; 32(3): [approx. 0]. Available in: http://www.revhematologia.sld.cu/index.php/hih/article/view/434.

Kettunen, J. A., Impivaara, O., Kujala, U. M., Linna, M., Mäki, J., Räty, H., ... \& Sarna, S. (2010). Hip fractures and femoral bone mineral density in male former elite athletes. Bone, 46(2), 330-335. https://doi.org/10.1016/j.bone.2009.10.008

Nancy, D.D. (2017). Lesiones deportivas. National Institute of Arthritis and Musculoskeletal and Skin Diseases. [Citado 5 de abril de 2019]. Disponible en: https://www.niams.nih.gov/es/informacion-de-salud/lesionesdeportivas.

Paajanen, H., Brinck, T., Hermunen, H., \& Airo, I. (2011). Laparoscopic surgery for chronic groin pain in athletes is more effective than nonoperative treatment: a randomized clinical trial with magnetic resonance imaging of 60 patients with sportsman's hernia (athletic pubalgia). Surgery, 150(1), 99-107. https://doi.org/10.1016/j.surg.2011.02.016

Pearson, L., \& Jones, G. (1992). Emotional effects of sports injuries: Implications for physiotherapists. Physiotherapy, 78(10), 762-770. https://doi.org/10.1016/S0031-9406(10)61642-2

Peter, V. F. (2015). Relationship among culture, education and sports. International research journal of management, IT and social sciences, 2(11), 38-42.

Pihl, E., Zilmer, K., Kullisaar, T., Kairane, C., Pulges, A., \& Zilmer, M. (2003). High-sensitive C-reactive protein level and oxidative stress-related status in former athletes in relation to traditional cardiovascular risk factors. Atherosclerosis, 171(2), 321-326. https://doi.org/10.1016/j.atherosclerosis.2003.08.015

Weidenhielm, L., Svensson, O. K., \& Broström, L. A. (1992). Change of adduction moment about the hip, knee and ankle joints after high tibial osteotomy in osteoarthrosis of the knee. Clinical Biomechanics, 7(3), 177-180. https://doi.org/10.1016/0268-0033(92)90033-Z

Abad, L. N., Vidal, V. R., \& Sabatés, H. R. R. (2020). Characterization of former athletes with gonarthrotic of Santiago de Cuba province. International Research Journal of Management, IT and Social Sciences, 7(3), 110-115. https://doi.org/10.21744/irjmis.v7n3.927 